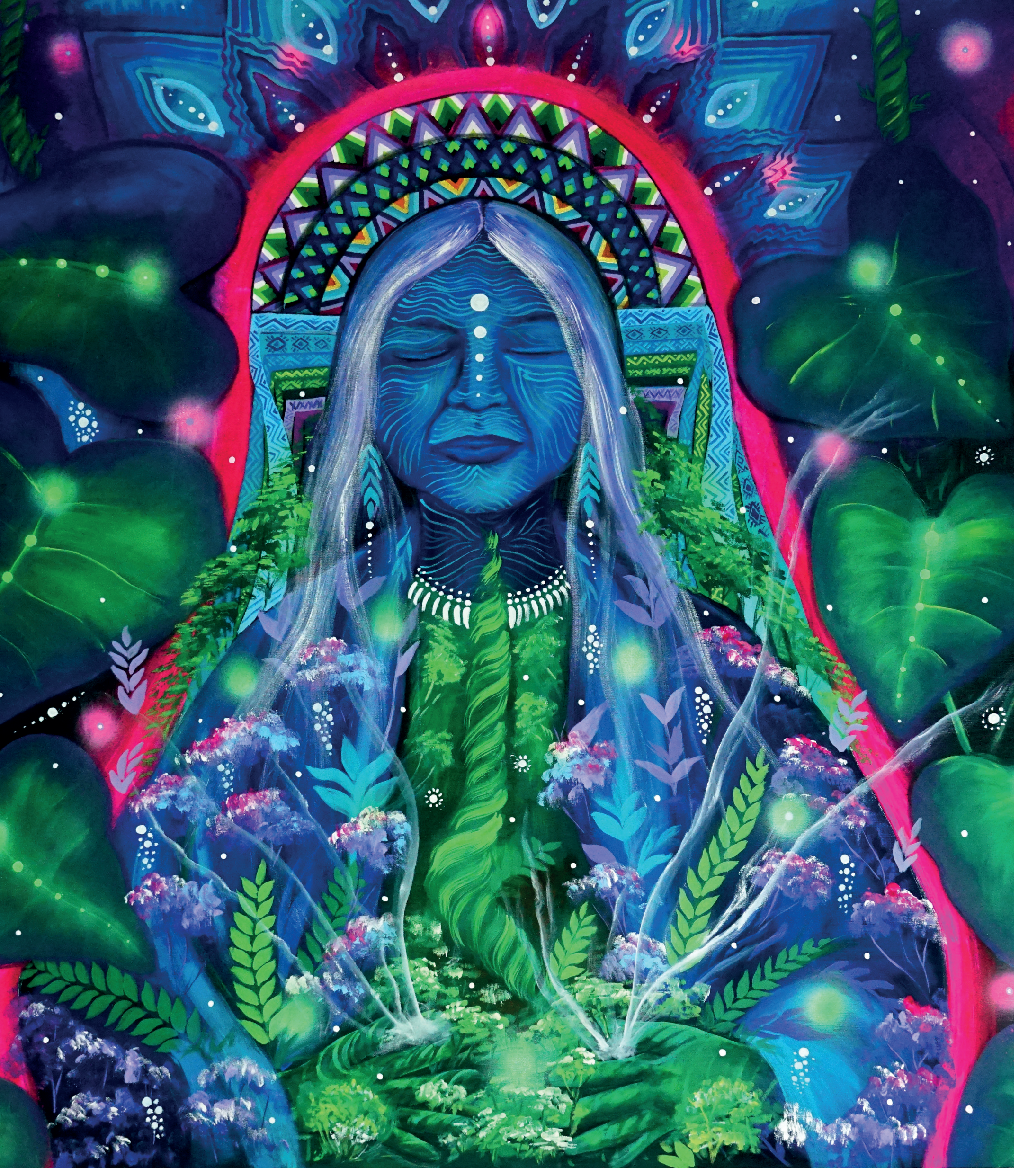




\section{Acción colectiva de las redes magisteriales que hacen comunagogía}

Collective Action of Teaching Networks Working on Comunagogy
Ação coletiva das redes do magistério que fazem comunagogía

Juan Carlos Jaime Fajardo*

Fecha de recepción: 28-09-18

Fecha de aprobación: 15-04-21

\section{PARA CITAR ESTE ARTÍCULO}

Jaime, F. (2020). Acción colectiva de las redes magisteriales que hacen comunagogía. Nodos y Nudos, 7(49). https://doi. org/10.17227/nyn.vol7.num49-8452
Sociólogo, Especialista en Políticas Públicas, Especialista en Aprendizaje autónomo, Magister en Estudios Sociales, Doctor en Educación, catedrático Universidad Pedagógica Nacional y maestro del Distrito de Bogotá. Correo: cajafa2005@yahoo.com . Orcid: https://orcid.org/0000-0002-4072-9950

\section{(c) (1) (5)}




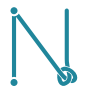

Volumen 7 N. ${ }^{4} 49$ julio-diciembre de 2020

ISSN: 0122-4328

ISSN-E: 2619-6069

pp. 75-88

\section{RESUMEN}

Este artículo de investigación expone cómo la acción colectiva de las redes de maestros, que se llaman a si mismas como alternativas, se está configurando en Bogotá, y cómo a través de sus prácticas educativas alternativas han transformado la escuela, la educación, los maestros y el territorio. Según las referencias teóricas, esta acción no se limita a reaccionar contra la política educativa oficial, por lo que trasciende el marco de interpretación de los movimientos sociales. Esto permite concluir que estas redes generan propuestas instituyentes en sus contextos, que se caracterizan como sentipensantes, tácticas, proactivas, permanentes y dispersas, por lo tanto es posible llamarla acción colectiva latente. Para esta investigación se estudiaron tres redes magisteriales de Bogotá aplicando el enfoque sociocrítico, cuya estrategia metodológica fue la narrativa, y se conformaron tres grupos de discusión. También se realizaron trece entrevistas semiestructuradas y se leyeron los documentos internos producidos por cada red.

Palabras clave: acción colectiva; transformación social; educación alternativa; comunagogía

\section{ABSTRACT}

This research article exposes how the collective action of the teaching networks that call themselves as alternative is getting setup, in Bogota, and also how, through their alternative teaching practices, they have transformed the school, the education, the teachers and the territory. According to the theoretical references, this collective action is not limited to react against official education policy, and so it transcends the frame of interpretation of social movements. This permits to conclude that these networks generate instituting proposals in their contexts, by means of their collective action, which is characterized as sentipensante, tactical, proactive, permanent and disperse. Thus it is possible to call it as latent collective action. For this research three teaching networks from Bogota were studied applying the socio critical approach. The methodological strategy was the narrative, and three discussion groups were conformed. Thirteen semistructured interviews were also done and the internal documents produced by each network were read too.

Keywords: collective action; social transformation; alternative education; comunagogia

\section{RESUMO}

Este artigo expõe de que maneira a ação coletiva das redes de professores, que se autodenominam alternativas, estão se estruturando em Bogotá. Além disso, como através das práticas educativas, têm transformado a escola, a educação, os docentes e o território. Segundo as referências teóricas, esta ação coletiva não se limita a reagir contra a política educativa oficial, senão que transcende ao marco de interpretação dos movimentos sociais. Assim, pode-se concluir que estas redes geram propostas que trazem mudanças aos seus contextos, mediante um trabalho comum que se caracteriza como sentipensante, tático, proativo, permanente e localizado em distintos lugares. Portanto, é possivel chamálo de ação coletiva latente. No que tange a esta pesquisa, foram estudadas três redes do magistério de Bogotá, usando o olhar sociocrítico. A metodologia foi a narrativa e se criaram três grupos de discussão. Da mesma forma, foram realizadas treze entrevistas semiestruturadas e foram lidos os documentos internos produzidos por cada rede.

Palavras-chave: ação coletiva; transformação social; educação alternativa; comunagogía 


\section{Introducción}

Lo expuesto hace parte de una investigación doctoral', que se basó en el enfoque socio-crítico, en la cual se develó el contexto de la política educativa en el que se inscriben las prácticas y la acción colectiva de las redes magisteriales. Al respecto Tarrow considera que "la acción colectiva no es una categoría abstracta que pueda situarse al margen de la historia y de la política" (1997, p. 23). En tal sentido, en la actualidad la política educativa se caracteriza por estar orientada por la teoría del capital humano, lo que ha incorporado una conceptualización empresarial en las instituciones educativas, ha fragmentado la práctica pedagógica y ha tendido a instrumentalizar al magisterio, entre otros aspectos, contexto en el que se agencian las practicas pedagógicas de las redes investigadas.

Las prácticas educativas de estas redes magisteriales se estudiaron en movimiento, es decir reconociendo sus tensiones, sus transiciones, sus construcciones de tejido social, sus temporalidades múltiples y sus trayectos, para lo cual se utilizó la matriz R- 5T, logrando establecer, en palabras de De Certeau (2000), tres maneras de hacer prácticas: las que rompen las fronteras disciplinares, las que están adentro y afuera de la escuela, y aquellas que tejen saberes. En estas prácticas emerge la comunagogía como una alternativa educativa.

Tal perspectiva se sintetiza al identificar que diversos procesos educativos, tanto en Oaxaca (México) como en Cauca (Colombia), se caracterizan por apuestas en común en sus intenciones, la planeación, los procesos de formación, la evaluación, etc., pero sobre todo en su horizonte educativo. Lo anterior - unido a perspectivas teóricas como la comunalidad propuesta por intelectuales oaxaqueños (Maldonado, 2003; Martínez, 2015), la comunitariedad propuesta por el CRIC (2004), y el sistema comunal propuesta por algunos bolivianos (Patzy, 2009)- permite nombrar estos procesos como comunagogía (Jaime, 2017a; 2019).

En suma, estas prácticas educativas se caracterizan por los siguientes horcones: 1) Soberanías

1 Jaime, J. (2018). La comunagogía: subjetividades alternativas en prócticas educativas de la acción colectiva de las redes magisteriales. [Tesis doctoral, sin publicar]. Bogotá: Universidad Pedagógica Nacional. epistémicas, que consisten en prácticas educativas que configuran matrices propias para la lectura de realidad de acuerdo a las cosmovisiones de las diferentes redes magisteriales, y estableciendo rupturas, por ejemplo, con el eurocentrismo y con el antropocentrismo, entre otras. 2) Decisiones y saberes compartidos, prácticas educativas en las que se reconocen saberes en el entorno y en los otros, haciendo partícipes a los estudiantes de las decisiones, por ende establecen rupturas con el autoritarismo y la educación bancaria de la que habla Freire. 3) Apuestas colectivas y dinamización de vínculos comunitarios, prácticas educativas que configuran emociones colectivas y tejen procesos organizativos, estableciendo rupturas con el racionalismo y el individualismo. 4) Construcción territorial, prácticas educativas que reconocen, apropian y proyectan el territorio en el que se inscribe la escuela, estableciendo ruptura con el aislamiento escolar. 5) Identidad con los proyectos comunitarios, prácticas educativas que se relacionan con las problemáticas y las esperanzas de las comunidades. Y 6) Emancipación de género, prácticas educativas que establecen rupturas con el patriarcado.

En relación con lo anterior, la comunagogía quiere decir que las prácticas educativas y los procesos de formación se caracterizan por lo común, se dan en la comunidad, con la comunidad y para la comunidad (Jaime, 2017a), y su esencia se fundamenta en las compartencias, que en esencia son prácticas educativas basadas en la alteridad para una subjetividad del nosotros, las cuales los pueblos originarios de Oaxaca las oponen a las competencias (Jaime, 2019; Martínez, 2015; Romero, 2010).

En esa perspectiva, el interrogante que orienta el presente texto es: ¿cómo se configura la acción colectiva de las redes magisteriales que hacen comunagogía en Bogotá? Este proceso investigativo se realizó a partir de las narrativas de 13 maestros integrantes de diferentes redes magisteriales, con las cuales se realizaron tres grupos de discusión con el fin de reconocer sus prácticas educativas. Las redes investigadas fueron: 1) la corriente Nuevos Maestros por la Educación (NME), 2) la Red Tulpa (RT), 3) la Red de Emisoras Alternativas del Territorio Sur (REATS), y 4) el proyecto colectivo de la institución José Celestino 
Mutis. Como espacio de confluencia de varias de estas redes se conversó con el Círculo Pedagógico de la ADE sobre prácticas emancipatorias. En este artículo se exponen algunas reflexiones sobre la acción colectiva de las redes magisteriales, y su relevancia radica en que dicha acción logra desenvolverse en medio de un contexto de la política educativa que busca la regulación social y el control del magisterio (Jaime, 2017b), pues, a pesar de la tendencia a la instrumentalización del docente este se abre paso a través de sus prácticas educativas.

El artículo se desarrolla en dos apartados: en primer lugar, se hace una reflexión conceptual sobre la acción colectiva de las redes magisteriales $y_{\text {, en se- }}$ gundo lugar, se presenta una propuesta analítica para comprender dicha acción.

\section{Reflexión conceptual sobre la acción colectiva de las redes magisteriales}

Por lo general los estudios sobre la acción colectiva se han centrado en los movimientos sociales, en este artículo se analiza cómo se expresa en las redes magisteriales dicha acción, para tal fin, inicialmente, se diferencia la relación movimiento social - movimiento pedagógico. Al respecto, Tarrow afirma que:

la acción colectiva contenciosa, aquella que es agenciada por quienes carecen de acceso real a las instituciones proponiendo reivindicaciones nuevas y que constituyen una amenaza para los otros, es la base de los movimientos sociales, por ser esta el principal recurso para enfrentar sus adversarios. (1997, p. 25)

Sin embargo, por sus propósitos, el movimiento pedagógico se diferencia de los movimientos sociales en que sus apuestas trascienden el carácter contestatario atribuido por varios investigadores (García, 2009; Tarrow, 1997). Al respecto, Martínez (2008) considera que el movimiento pedagógico no es simplemente contestatario, es una propuesta alternativa al poder dominante en cuanto a las visiones de escuela, maestro y pedagogía. De igual manera, Martínez et ál. consideran que el movimiento pedagógico "sin ser indiferente a las luchas sociales, presenta otra naturaleza, un tipo de lucha más cercano a la conquista de una subjetividad en lo pedagógico, lo político y lo social" (citados por Martínez, 2008, p. 34). Pueden existir otros movimientos de similar naturaleza al pedagógico, es decir que su único recurso para confrontar sus adversarios no sea lo contencioso, pero no es el interés del presente texto.

Por su parte, García (2009) imputa a la acción colectiva la capacidad de reconstituir el poder del Estado y atribuye a esta alcances similares a los de los movimientos sociales, no obstante se toma distancia de esta perspectiva, ya que puede invisibilizar acciones colectivas magisteriales que realizan transformaciones cotidianas y escolares, por ende políticas, sin llegar a reconstituir el poder estatal ${ }^{2}$, y sin negarse a ello, pues la acción colectiva de las redes magisteriales realiza transformaciones sociales sin necesidad de pasar por el Estado.

Así pues, aunque todo movimiento es una acción colectiva, no toda acción colectiva es un movimiento social (Jiménez, 2007; Torres, 2007), no obstante existen relaciones entre estos, por ejemplo las redes magisteriales están presentes y se potencian a la par con el movimiento pedagógico, pero su actuar no depende de este, ya que puede presentarse la acción colectiva de las redes magisteriales, como sucede en varios paises de la red lberoamericana, pero no existe a la par un movimiento pedagógico.

Ahora bien, otros investigadores relacionan el trabajo en red con el ámbito cultural, y se da una sincronía entre movimientos sociales y colectivos educativos, como en algunos pueblos indígenas (CRIC, 2004) o campesinos en Brasil. Para Ibáñez (2000), el campo común entre los movimientos sociales y educativos es precisamente lo expuesto como cultura trasformadora, pues es claro que si las redes pretenden ser verdaderamente críticas y alternativas no pueden desvincular de sus propósitos el contexto social. En otras palabras, para el autor, si las redes no se constituyen a su vez como movimientos sociales sus acciones quedarían restringidas a cuestiones metodológicas y contemplativas, alejadas de la acción y desvinculadas de un compromiso real, vital y

2 Engels diferencia entre poder social y poder político, el primero referido a los poderes no estatales, en los cuales puede inscribirse el poder del maestro en el aula o el empoderamiento social constituido por estas redes en los territorios. Diferencia establecida por Engels en el Discurso ante la tumba de Marx (1883). 
humano. A pesar de tal situación, existen redes magisteriales que no llegan a ser movimiento social, como las aquí investigadas, más no por ello dejan de ser instituyentes.

En relación con lo anterior, Ibáñez (2000) afirma que resulta imprescindible que la educación o la formación que se otorgue desde estos movimientos educativos sea crítica y reflexiva, es decir que lea el contexto para transformarlo, dado que desde esta postura las acciones pedagógicas y sociales ayudan al empoderamiento de los grupos socialmente excluidos, construyendo con ello una cultura transformadora ${ }^{3}$. De cualquier forma, la conexión entre los movimientos educativos críticos y los movimientos sociales tiene como objetivo que las diferentes organizaciones puedan unir propósitos y ganar mayor visibilidad de sus propuestas. Se comparte con este autor la necesidad de una educación crítica que transforme los contextos donde se inscriben las prácticas pedagógicas, pero se considera que la relación entre la acción colectiva de las redes magisteriales con el movimiento social es relativa, más aún cuando vivimos en una sociedad en movimiento, donde la categoría de movimiento social no alcanza a dar cuenta de la riqueza social existente en la movilización (Zibechi, 2017).

En esa dirección coinciden Torres (2007) y Martínez (2008), en que las acciones colectivas de las Organizaciones Populares Urbanas (opU), como las redes pedagógicas, no pueden catalogarse como movimientos sociales, a pesar de sus aportes a estos y sin negar su potencial transformador. Sus argumentos radican en que la acción colectiva no se restringe, ni se limita, al trabajo de los movimientos sociales, sino que se considera como una potencia que promueve formas de transformación sobre la realidad local, caracterizada por su vocación de lo alternativo, configurando empoderamiento social. Como se afirmó, no toda acción colectiva es movimiento social, esta distinción es relevante, ya que permite reconocer la

3 Hay que rechazar aquellos planteamientos educativos que se reclaman críticos pero que no tiene en cuenta, en la práctica, a la totalidad del alumnado, o las de quienes, desde el ámbito social, no consideran que la mayoría de la población sea destinataria, desde el principio, de sus prácticas. Se trata de pelear por la igualación económica y educativa, pero también de generar acciones que consigan conectar las preocupaciones más inmediatas de numerosos sectores sociales. (lbáñez, 2000, p. 24) capacidad transformadora de la acción colectiva de las redes magisteriales, sin tener que darles a estas el carácter de movimiento social para reconocer su potencial instituyente, aclarando que tampoco se opone a ellos. En sintesis, reconocer el movimiento pedagógico y la acción colectiva de las redes magisteriales con sus propias dinámicas, y no descalificar su potencial transformador por no constituirse en movimiento social, es el punto de partida propuesto para su comprensión.

Por ende, se considera que la acción colectiva de las redes magisteriales no se limita a lo contencio$\mathrm{so}^{4}$, pues se presentan acciones colectivas religiosas, festivas, deportivas y educativas, entre otras, que no se limitan a lo contestatario, sino que son formas de resistencia proactiva, como sugiere (Martínez, 2008). En tal dirección, lo expuesto por Touraine (1987) debería matizarse: "Solo cuando las acciones colectivas tratan de transformar las relaciones de dominación social ejercidas sobre los principales recursos sociales - producción, conocimiento, reglas éticas- cabe la expresión movimiento social" (citado por Torres y Torres, 2015, p. 94), ya que dichas transformaciones también las producen las redes magisteriales, sin que por ello sean movimiento social, aunque claro está puedan hacer parte de este. Al respecto, queda el interrogante si ¿las transformaciones producidas por las redes magisteriales, cuestionando la dominación, llevaría a asimilarse como movimiento social?

Si bien en la acción colectiva están presentes las creencias y valores o, en palabras de Delgado (2007), los marcos de interpretación que la motivan, se requiere además analizar los cambios que se producen tanto en la subjetividad, como en los procesos educativos, como resultado de tales acciones. De ahí que se considera limitado quedarse en el porqué de la acción colectiva propuesto por la teoría de los nuevos movimientos sociales, o únicamente en el cómo desde la teoría de movilización de los recursos (Massal, 2014; Torres, 2007), exigiéndose entonces una perspectiva

4 Para Tarrow:

hay muchos tipos de acción colectiva, desde las votaciones y la afiliación a grupos de interés a los torneos de bingo y los partidos de futbol. Pero no son estas las formas de acción más características de los movimientos sociales. Los movimientos plantean sus desafíos a través de una acción directa decisiva contra las elites, las autoridades u otros grupos o códigos culturales. (1997, p. 22). 
acorde con las nuevas expresiones de la movilización pedagógica.

Además, llama la atención aquellos énfasis que se centran en las transformaciones del sujeto, pues, antes que indagar por las formas organizativas y sus motivaciones, interesa ver cómo se va configurando la subjetividad política como parte de la emancipación. Perspectiva que se comparte en esta exposición.

En ese sentido, se parte de reconocer lo que Martínez considera respecto a que no toda forma organizativa de los maestros es transformadora, de ahí que la autora afirme que:

Se toma distancia de esas formas de conexión e interacción, en las que se ve al sujeto como un "recurso" para asegurar cambios necesarios hacia la eficacia de los intereses de la sociedad de control y de la globalización en red. $(2008$, p. 19)

Este hallazgo es relevante al momento de estudiar la acción colectiva de las redes magisteriales, pues desconocerlo implicaría darles un carácter transformador a organizaciones magisteriales que no lo son, de ahí que sea necesario identificar, más allá de lo organizativo, las motivaciones, las acciones y las transformaciones de la perspectiva instituyente por las cuales se organizan los maestros.

Concuerdan las investigaciones de Martínez (2008) y Torres (2007) en que no toda forma organizativa construye identidad, ni genera transformación. En el primer caso, advierte Martínez, existen redes educativas funcionales al sistema que someten al maestro a intereses externos. En el segundo caso, señala Torres, se generan formas de organización social por intereses puntuales que no configuran identidades a pesar de tener cierta estabilidad.

Son los sujetos, en este caso los maestros, los que asumen posturas críticas, las agencian y posibilitan su incidencia, más allá de la forma organizativa. En las redes investigadas se produce la formación de maestros alternativos (Jaime, 2018), quienes transitan hacia la soberanía epistémica, ya sea reconociendo en la escuela posibilidades, concibiendo la naturaleza como complemento, leyendo la realidad de manera compleja o concibiendo el tiempo como oportunidad politica y a los estudiantes como sujetos. En tal sentido, Martínez (2008) evidencia el papel fundamental que tienen las redes en la constitución de sujetos y saberes, principalmente en los maestros que participan en las acciones colectivas.

Los alcances en la constitución de sujetos políticos se hacen más potentes cuando se encuentran con otros para construir tejido social, estableciendo relaciones y vínculos sociales de reciprocidad. Así mismo, para Martínez: "las conexiones, entramados, mallas humanas, interacciones -que caracterizan a las redes- se convierten en soporte para crear tejido social" (2008, p. 137). Tales construcciones de tejido social pueden ir materializando el movimiento pedagógico.

Por lo anterior, se afirma que la acción colectiva de las redes magisteriales tiene capacidad transformadora en y desde la vida local y cotidiana, construyendo el trayecto de lo alternativo, sin esperar hasta el cambio de las estructuras, aunque sin oponerse a ello. Las huellas instituyentes de la acción colectiva de las redes magisteriales se expresan en la subjetividad de sus actores, la transformación de los contextos escolares, la emergencia de relaciones y vínculos sociales, y en la construcción de tejido social, lo cual se expone a continuación.

\section{Propuesta analítica para comprender la configuración de la acción colectiva de las redes magisteriales}

Se parte de afirmar que, para la comprensión de la acción colectiva de las redes magisteriales se requiere una perspectiva analítica que reconozca su potencial instituyente, y que supere estudiarla como un movimiento social, aunque pueda o no hacer parte de este. En tal dirección, se presentan a continuación una serie de ámbitos que caracterizan la acción colectiva de las redes magisteriales que hacen comunagogía en la ciudad (Véase figura 1), los cuales se constituyen en la base para una matriz analítica. Estas formas de la acción colectiva son: sentipensantes, proactivas, permanentes, tácticas y dispersas, todas ellas nutridas con múltiples prácticas educativas. Se aclara que dichos ámbitos en la realidad empírica se entrelazan, por ende el esquema propuesto es para enfatizar en algunos matices existentes. 


\section{Configuración de la acción colectiva de las redes magisteriales que hacen comunagogía en la ciudad}

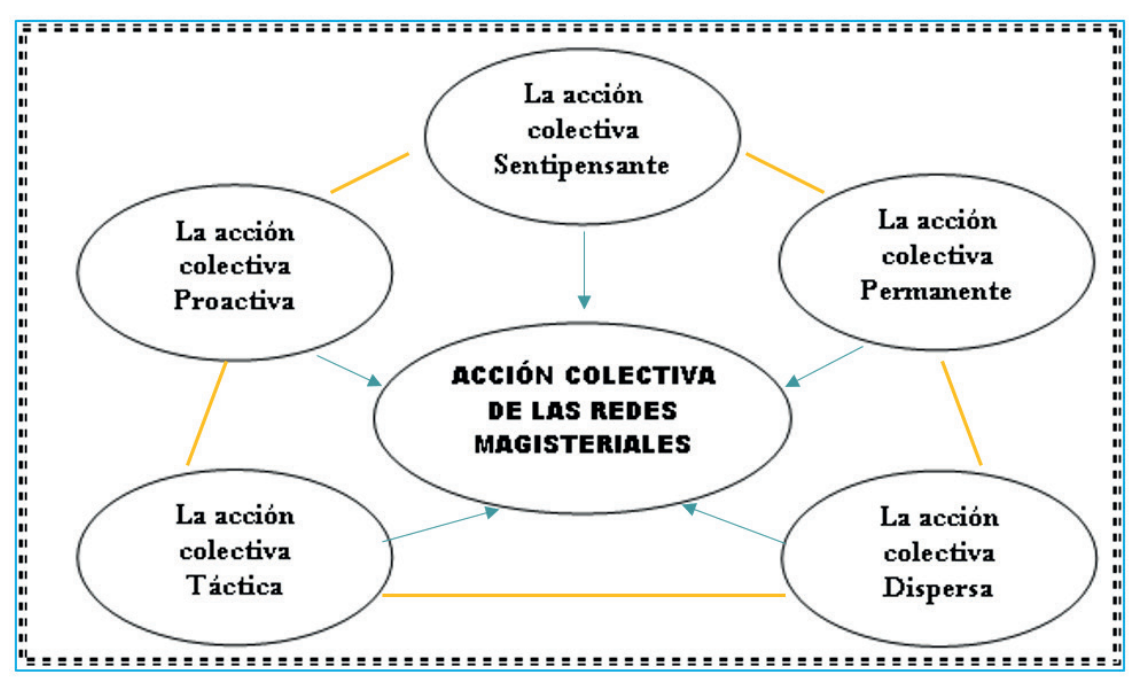

Figura 1. Manifestaciones de la acción colectiva en las redes magisteriales. Fuente: elaboración propia

\section{La acción colectiva de las redes magisteriales es sentipensante}

Se parte de lo expuesto por Maturana (2001) respecto a que no hay acción humana sin una emoción que la funde, pues la absolutización de lo racional en la explicación de la acción colectiva, como lo argumentó Mancur Olson (1992) en su obra La Lógica de la Acción Colectiva, desconoce no solo parte de las motivaciones, sino también los trayectos y las producciones, tanto en la subjetividad como en los contextos de tales acciones.

Para Olson, la tendencia individual es no participar de la acción colectiva y si lo hace es por incentivos individuales. En el desarrollo de la teoría de juegos para explicar la acción colectiva se da un tránsito de lo paramétrico a lo estratégico, algunos de los juegos propuestos son: dilema del prisionero, dilema del gallina y dilema del altruista, entre otros, en los cuales el actor tiene que decidir entre alternativas que valora de manera diferente de acuerdo al entorno estratégico, pero basado en cálculos racionales, en lo que se incluye también la teoría evolutiva de juegos como el Juego del Halcón o de la Paloma (Miller, s.f.). Estas perspectivas racionalistas se consideran limitadas para dar cuenta de la acción colectiva de las redes magisteriales por no incorporar la dimensión emocional, y por limitar la acción al costo-beneficio.

En contravía, algunas prácticas de estas redes expresan la importancia de lo afectivo en su acción colectiva, al respecto manifestaron que:

en muy pocos lugares y en muy pocos momentos de la vida uno consigue amigos, es decir, personas que comparten o no maneras de pensar, pero que están dispuestas a aprender y a recorrer el camino de la vida al lado de uno, y creo que este colegio de alguna manera me ha permitido trascender esos lazos de lo laboral y generar relaciones de carácter afectivo con otras personas. (Grupo Discusión Mochuelo, 1 dic de 2016)

La creación de vínculos afectivos entre los integrantes de las redes magisteriales, y de estas con las organizaciones sociales, es frecuente, así mismo que en las prácticas de reconocimiento del territorio emergen afectos tanto en maestros y maestras, como en estudiantes:

se han estrechado lazos entre los representantes de padres de familia con los padres que tienen talentos, los muestran los papitos de los chicos con dificultades en las drogas, con los niños en la parte del sector productivo 
que involucra a los jóvenes. (Integrante NME, comunicación personal, agosto 2016)

Adicionalmente, los vínculos se tejen con la comunidad cercana a la escuela:

los profes que llevan más tiempo (el caso del profe Yesid o de Liliana) han generado vinculos con las personas del sector y ellos reconocen la escuela como un escenario desde el cual estamos intentando trasformar su vida personal y también el de su familia. (Grupo Discusión Mochuelo, diciembre 2016)

Incluso, gran parte de las prácticas educativas que se realizan de manera extraescolar, como los recorridos por los territorios, las tertulias y los cine foros comunitarios, entre otras, están mediadas por apasionamientos de los maestros y maestras partícipes:

por lo menos en lo personal me motiva poder intercambiar nuestras experiencias, en esa metodología de confrontación de crítica y autocrítica. También porque tenemos unidades, porque nos interesa mucho el plan pedagógico desde una conciencia con los estudiantes y con la sociedad. (Grupo Discusión NEM, noviembre 2016)

Incluso, se crean afectos entre los integrantes de estos colectivos:

pues si bien ya no trabajamos juntos la amistad continúa y el trabajo político continúa, nos hemos seguido organizando cada uno desde su comunidad educativa, se fortalecen los lasos de amistad, digamos que se trasciende de la relación exclusivamente laboral a una relación mucho más fuerte con lazos de amistad y afectivos. (Integrante Tulpas, comunicación personal, septiembre 2016)

Claro está, tales prácticas emotivas se imbrican con apuestas políticas, razonadas y planeadas, por ejemplo: para la red NME se educa para la transformación social, y para el colectivo del Mochuelo se educa para construir el territorio, es decir que además de lo emotivo están presentes fines o propósitos racionales en su acción colectiva.

Sobre el papel de las emociones en la acción colectiva, vale señalar los aportes hechos desde la sicología a principios del siglo XX, como la corriente de la sicología de masas propuesta por Le Bon en 1895, la corriente de los comportamientos colectivos a partir de las creencias, valores morales e ideologías, propuesta por la escuela de Chicago en los años 20, y la teoría de la frustración relativa en la década de los sesenta (Massal, 2014), perspectivas que explicaban la acción colectiva como resultado principal de lo irracional o emocional.

Es reconocido por varios autores, entre ellos Torres (2007) y Massal (2014), la preponderancia de las explicaciones racionalistas de la acción colectiva en la segunda mitad del siglo $x x_{\text {, }}$ sin embargo, recientemente se ha puesto en el centro del debate las emociones como explicación de la acción colectiva, así lo exponen James Jasper y sus colegas Jeff Goodwin y Francesca Polletta, también Flam y King, la tesis central de estas últimas autoras, es que las emociones constituyen el enlace entre la micro y la macropolítica (Massal, 2014).

Por eso, al indagar en las redes magisteriales los porqué de su acción colectiva, sobre todo su permanencia y sus transformaciones, se evidencia una mezcla frecuente de sentimientos y razones ${ }^{5}$, ya sea sentir por el otro en un ejercicio de alteridad, por el proyecto político o para reconfigurar las propias subjetividades. Por lo anterior, se considera relevante entender la acción colectiva como sentipensante, tal y como nombra Fals Borda a los sujetos y sus prácticas sociales (citado por Moncayo, 2009), en las cuales coexisten simultáneamente sentimiento y reflexión.

\section{La acción colectiva de las redes magisteriales es proactiva}

A diferencia de la acción colectiva contenciosa que propone Tarrow (1997), como la forma principal de los movimientos sociales, las redes magisteriales se movilizan principalmente por una perspectiva de resistencia proactiva como lo sugiere Martínez (2008), es decir, su horizonte de acción lo constituye la esperanza ante lo injusto de una situación, y no se motiva únicamente por la identificación de un responsable político externo, como lo sugieren Snow y Benford con la teoría de marcos de acción (citados por Massal, 2014). En este caso, las redes magisteriales actúan por un compromiso ético y por proyectos

5 Resultados del trabajo de campo realizado por el autor para la investigación doctoral mencionada. 
colectivos, por ello se evidencian una serie de creaciones en cada uno de los proyectos agenciados por estas redes, en los cuales si bien el Estado es responsable de la situación de injusticia en la educación, el accionar de las redes magisteriales se enfoca en asumir el camino como compromiso propio, y no se limita a la resolución únicamente por parte del Estado.

Fueron frecuentes los relatos de maestros y maestras sobre la construcción de nuevos currículos, desde contenidos, didácticas, intenciones, etc., así como la realización de proyectos colectivos sin esperar que las instituciones educativas los avalen o financien, aunque sin oponerse a ello, es decir, la resistencia proactiva de estas redes es parte fundamental de su quehacer.

Al respecto, una maestra relata que: "tengo ahora una gran transformación, tengo mayor seguridad, le apuesto a cosas nuevas. Antes me daba mucho miedo apostar a cosas nuevas porque me daba miedo a salirme del currículo" (Integrante NME, comunicación personal, agosto 2015).

Tal ámbito proactivo de la acción colectiva lleva a romper con rutinas escolares de los maestros que integran estas redes, en palabras de uno de ellos:

Por ello decidi dejar de lado los textos escolares y centrarme en consultar, buscar, apoyarme en material audio visual, como teórico propio o de otros colegas. Además de lo anterior hay que vivenciar experiencias en varios aspectos, la búsqueda de fuentes de conocimiento variadas, orales, escritas, tecnológicas, ancestrales, el invitar otras personas de la comunidad al salón, la creación escrita, argumentativa, artística, entre otras muchas cosas que nos deben acompañar constantemente. (Integrante NME, comunicación personal, julio 2016)

\section{De igual manera,}

digamos que en un momento inicial mi práctica pedagógica estaba más ligada al cumplimiento de esos curriculos, en cierto sentido algo vertical, estricto. Eso se ha venido transformando, el poder involucrar las practicas del territorio, poder llevar precisamente esa teoría que se desarrolla en las aulas al reconocimiento de la realidad y al contexto en el que está involucrada la institución educativa. (Grupo discusión REATS, comunicación personal, 2016)

En tal dirección, las redes magisteriales a partir de sus apuestas colectivas, entre otras acciones, abrazan el territorio estrechando lazos entre la escuela y el barrio, práctica en la cual antes que exigirle al Estado esta posibilidad re-actúan de manera propositiva como parte de sus utopías políticas.

\section{La acción colectiva de las redes magisteriales es permanente}

A diferencia de las protestas, insurrecciones y revueltas, la acción colectiva de las redes magisteriales es permanente, en ese sentido, estas no requieren una elaboración de dirección o guía como lo expone la teoría de marcos de interpretación, la cual no concibe la acción espontánea, pues en dicha perspectiva transitar de lo injusto a identificar un responsable y actuar para lograr el cambio, o pasar de tender puentes a la extensión, la ampliación y la transformación, requiere de una apuesta racional de la acción (Massal, 2014). Si bien las redes magisteriales pueden transitar el mencionado trayecto, también realizan acciones colectivas cotidianas rompiendo con la idea instrumentalista de la movilización, donde habría un "encuentro" entre el individuo dispuesto a movilizarse y un actor movilizador que logra captar la atención del primero (Massal, 2014).

Tales prácticas de la acción colectiva van dinamizando cotidianidades escolares de manera permanente. Al respecto:

con lo de la escuela popular se empieza a impactar, yo creo que lo que está haciendo el profe Johan con lo de Música está tocando un poco el área de artes, porque los chicos, ya sea poco o mucho, ya discuten esto en el colegio. La existencia de la huerta, lo que se ha hecho con los cine foros, eso genera unas dinámicas cotidianas totalmente diferentes de lo que es el colegio. El colegio tiene una percepción hacia afuera, por ejemplo, con la junta de acción comunal, con la asociación de padres, entonces se va dando tejido social. (Grupo discusión NME, noviembre de 2016)

Tales expresiones de lo permanente en la acción colectiva van haciendo que los procesos educativos se transformen:

la materialización de ese jardín agroecológico funciona como un ambiente de aprendizaje, donde los maestros de diferentes áreas del conocimiento tienen una relación con la tierra, pero con diferentes dimensiones, a saber, 
con la construcción de una cúpula donde aplica la matemática y tiene alcances en la educación ambiental. El profe de filosofía también cultiva unos ejercicios de trabajo muy interesantes alrededor del pensamiento, de la filosofía más profunda y más que aprenderse los griegos, el profe hace unas cosas bien bonitas, esa es otra forma de materialización del trabajo. (Integrante colectivo del Mochuelo, comunicación personal, mayo 2016)

Este carácter permanente de la acción colectiva de las redes magisteriales tampoco responde al enfoque de ciclos de la protesta como lo sugieren algunos estudiosos del tema, como Tilly y Tarrow (citados por Massal, 2014), sino que las redes magisteriales presentan un actuar cotidiano. De ahi que, la acción colectiva de las redes magisteriales no sea cíclica, episódica, o no dependa de las estructuras de oportunidad, por el contrario son pequeñas movilizaciones que están produciendo grandes transformaciones escolares de manera permanente. Estas acciones colectivas se acercan a lo que Torres (2007) reconoce en las opu ${ }^{6}$ como la organización de la vida cotidiana y los espacios donde se construyen los vínculos sociales más significativos, elaborando representaciones sobre sí y los demás, acciones que se expresan tanto en la escuela como en el territorio, construyendo vínculos y transformaciones tanto en la subjetividad como en el contexto.

Por ello, es permanente la emergencia de prácticas educativas, ya sea las que rompen las fronteras disciplinares dentro o fuera de la institución escolar, o las que comparten saberes, las cuales se mantienen y realizan trascendiendo los cronogramas y espacios escolares. Este carácter constante de la acción colectiva de las redes magisteriales, fruto de lo mencionado anteriormente, se expresa, además, en reflexiones colectivas de los maestros sobre su quehacer, en prácticas y proyectos como la promoción de emisoras escolares, en persuadir a sus colegas en la necesidad de participación de los proyectos pedagógicos, en construir tejidos de articulación con otras redes y organizaciones sociales, entre otras cotidianidades que van transformando a los sujetos, la educación, la escuela y los territorios.
Si bien esta es una característica de la acción colectiva de las redes magisteriales que hacen comunagogía, no quiere decir que no suceda en los movimientos sociales, lo que se advierte es que, antes que revueltas o insurrecciones de las redes magisteriales, estas actúan principalmente de manera cotidiana y permanente.

\section{La acción colectiva de las redes magisteriales es táctica}

Debido a los mecanismos de control y regulación que se están imponiendo en la escuela actual, como los procesos de evaluación internos y externos que pretenden instrumentalizar a los maestros y maestras, los integrantes de las redes magisteriales no se subordinan (Jaime, 2017b), por el contrario hacen uso de la política educativa, expresando lo que afirma De Certeau (2000): los sujetos son usuarios de un poder, con capacidad de fabricación en sus maneras de hacer las prácticas, reinventando lo cotidiano. En esa perspectiva la normatividad y la institucionalidad establecidas para la implementación de la política educativa es usada y burlada por estas redes, a pesar de la tendencia al mayor control y regulación social de maestros y maestras.

Al respecto, una maestra relata que:

Las ferias pedagógicas son institucionales, esas actividades se dan y se trabaja junto con ellos, pero se pierde el foco si se realizan por realizarlas, en cambio estas actividades si se involucran a un proyecto educativo alternativo es muy diferente. (Integrante NME, comunicación personal, agosto 2016)

Sobre el uso táctico del gobierno escolar, los participes de estas redes magisteriales afirman que:

\begin{abstract}
estaban en la calle y yo en el consejo académico diciendo que los profesores tenían que estar y tocaba cuidar mucho los niños, pero era para que ellos vieran otras formas de hacer y después entonces otros tenían que explicar y resolver la campaña de Pitágoras. Yo les digo la tarea es dejarnos contagiar y contagiar a otros. (Integrante REATS, comunicación personal, marzo 2016)
\end{abstract}

Se adoptan programas de empresas aledañas a los colegios, al respecto una maestra dijo:

6 Organizaciones Populares Urbanas en los territorios donde se inscriben sus procesos educativos. 
Hay una cosa curiosa, el colegio por estar en un contexto de conflicto ambiental tan fuerte como el parque minero y el relleno generó mucha focalización de recursos para proyectos. Yo personalmente creo que lo he aprovechado y potenciado mucho, porque en diálogo con esas instituciones como el Jardín Botánico, Hospital Vista Hermosa, la Institución Santa Fe (que manejaban proyectos de distención y la UADESP que es la del relleno de servicios públicos), llegan a la institución y hay una cosa muy clara y es que los profes se quejan de que llegan muchas cosas, yo a eso no le veo problema siempre y cuando uno tenga un diálogo que diga: este es mi proyecto, usted me puede apoyar acá. (Integrante colectivo del Mochuelo, comunicación personal, mayo 2016)

Lo táctico se evidencia, además, en cómo las redes magisteriales hacen uso de: el Proyecto Educativo Institucional (PEI), las funciones comunitarias exigidas en la evaluación de desempeño, los aspectos de la política educativa como la reorganización curricular por ciclos, y la manera como transforman el día E de la llamada excelencia en el día de la emancipación o en el dia $R_{1}$ es decir de la ruralidad, entre otras maneras de su hacer pedagógico para agenciar sus apuestas educativas. Esta acción colectiva táctica va estableciendo rupturas con lo instituido y con los procesos de regulación social imperantes en la escuela actual.

\section{La acción colectiva de las redes magisteriales es dispersa}

Otra característica de la acción colectiva de estas redes es su dispersión. Con frecuencia la mirada investigativa sobre la acción colectiva se ha puesto en los movimientos sociales, las protestas y las insurrecciones, casi todas en relación con el Estado, a saber, en concentraciones humanas que reclaman sus demandas, pero poco en acciones colectivas dispersas y cotidianas 7 , en el caso de estas redes magisteriales, desde lo disperso, van configurando acciones colectivas que han llevado a la transformación escolar, en ocasiones aportando a insurrecciones, protestas o revueltas. Esta dispersión sucede en territorios, áreas del saber y proyectos, en las que se expresa y

7 En Bogotá, las investigaciones de Martínez (2008) sobre las redes pedagógicas, Torres (2007) sobre Organizaciones Populares Urbanas (opu) y Torres (2015) sobre el caso de Asamblea Sur, dan cuenta de las cotidianidades de la acción colectiva en Bogotá. se configura el trayecto de la acción colectiva. Dicha dispersión a su vez se constituye en un mecanismo de autoprotección de estas ante las intenciones de cooptación de instituciones estatales, debido al amplio espectro de su actuación. Como dice Zibechi (2006), al analizar las luchas urbanas en El Alto: "Lo estatal se dispersa, lo uno cede paso a lo múltiple, por lo tanto, no hay control de la población" (citado por Torres, 2013, p. 171).

Entonces, es frecuente encontrar en un mismo dia la diversidad dispersa de la acción colectiva de estas redes, principalmente en horarios y lugares extra escolares, como en fines de semana en diferentes actividades y localidades de la ciudad donde maestros integrantes de las mismas realizan prácticas educativas como son: los recorridos por los territorios, círculos de la palabra, ciclo recorridos, cine foros, exposiciones de museos populares y jornadas ambientales, entre otras desde donde se van transformando los contextos escolares y los sujetos participantes, pero sin que para ellos se requiera una concentración de estos, al contrario desde la dispersión actúan colectivamente, en palabras de Torres y Torres (2015) su escala de acción puede ser interlocal o supra local.

\section{Balance: la acción colectiva de las redes magisteriales es latente}

En sintesis, expuestas las diferentes expresiones de la acción colectiva de las redes magisteriales que hacen comunagogía se va mostrando su configuración, y a su vez se van sentando las bases para la construcción de una propuesta analítica y conceptual, al menos en el plano descriptivo, que permita mayor comprensión de esta realidad social ${ }^{8}$, esta conceptualización descriptiva la denomino de manera preliminar: "acción colectiva latente", debido a que desde diferentes maneras de la acción colectiva, silenciosas y manifiestas, trascendentes y tenues se van produciendo las transformaciones escolares, sin que en dicho proceso se presente un alto en el trayecto, de ahí su carácter latente.

8 En el mismo sentido, sobre la necesidad de conceptualizar la riqueza y particularidades de la acción colectiva en la ciudad actual, Torres (2015) ha propuesto nominarla como Acción Colectiva Territorial. 
Lo central es que estas expresiones de la acción colectiva de las redes magisteriales establecen rupturas con aquellas que centran su actuar exclusivamente en relación con el Estado, y establecen rupturas con las concepciones rígidas sobre los movimientos sociales, semejándose entonces a lo que Zibechi (2017) Ilama la sociedad en movimiento.

En estos procesos de la acción colectiva se genera entre sus partícipes una identidad de pertenencia (Becerril, 2014), tanto a las redes como a los procesos educativos que se agencian, fortaleciendo una cultura nosótrica (Ángeles, 2013) debido al fortalecimiento de sus apuestas colectivas. Adicionalmente, esta manera de configuración de la acción colectiva de las redes magisteriales está relacionada con la subjetividad telúrica, en palabras de Vasco (2004), esto es, que el territorio se constituye vital para sus apuestas educativas, y en la perspectiva de la comunalidad lo alternativo de dicha acción está relacionada con los diferentes ámbitos de la comunagogía, es decir en los horcones ya mencionados.

En suma, la acción colectiva de estas redes aporta a la transformación social, expresada en lo educativo, lo escolar y en la subjetividad de quienes participan de ella, en otras palabras, se dan transformaciones políticas que van configurando poderes sociales (siendo esto lo fundamental), de ahí la importancia de su comprensión para visibilizarla, articularla y proyectarla.

\section{Referencias}

Ángeles, I. (2013). La comunalidad práctica social del pueblo IñBakuu, dimensiones pedagógicas, el caso de San Sebastián Tlacolula. [Tesis doctorado en Educación, Universidad Pedagógica Nacional México].

Becerril, A. (2014). El Centro de Estudios Superiores Indígenas Kgoyom, una estrategia para la continuidad y autonomía totonaca. [Tesis de maestría, Universidad Autónoma Metropolitana].

Consejo Regional Indígena del Cauca (cric). (2004). ¿Qué pasaría si en la escuela...? 30 años de construcción de una educación propia, programa de educación bilingüe e intercultural. Consejo Regional indígena del Cauca Pebi.

De Certeau, M. (2000). La invención de lo cotidiano I. El arte de hacer. Universidad Iberoamericana.
Delgado, R. (2007). Los Marcos de la acción colectiva y sus implicaciones culturales en la construcción de ciudadanía. Universitas humanistica, (64), 41-66. http://revistas.javeriana.edu.co/index.php/univhumanistica/article/ view/2165/1403

Garcia, L. (2009). La potencia plebeya: acción colectiva e identidades indigenas, obreras y populares en Bolivia. Clacso. http://bibliotecavirtual.clacso.org.ar/ar/libros/coedicion/ linera/linera.pdf

Ibáñez, J. (2000). Movimientos y redes para una cultura transformadora. Tabanque, (17), 11-32. http://jei.pangea. org/edu/c/e-movim-redes.htm

Jaime, J. (2017a). La comunagogía: una manera de dinamizar procesos educativos alternativos. Argumentos, 30 (83), 197-218. http://www.redalyc.org/articulo. oa? id $=59552649009$

Jaime, J. (2017b). Redes magisteriales en medio de la regulación social y el control docente. Educación y Ciudad, (33), 29-40. https://dialnet.unirioja.es/servlet/ articulo?codigo $=6213574$

Jaime, J. (2018). La comunagogía y la formación de maestros alternativos. Rutas de formación, 54-59.

Jaime, J. (2019). La comunagogía y la inclusión. Revista Educación y cultura, (131), 16-20.

Jaime, J. y Jiménez, C. (2007). Acción colectiva y movimientos sociales, nuevos enfoques teóricos y metodológicos. México: Universidad Autónoma Chapingo. http://www. contemporaneaugr.es/files/Tema\%201_\%20Teor\%C3\%ADas\%20Movimientos\%20Sociales.pdf

Maldonado, B. (octubre de 2003). La comunalidad indígena. Segunda edición cibernética. http://www.antorcha.net/biblioteca_virtual/politica/comunalidad/comunalidad.html

Martínez, J. (2015). La Educación Comunal. Tomo ॥I, Cllo. Casa de las Preguntas.

Martínez, M. C. (2008). Redes pedagógicas. La constitución del maestro como sujeto político. Magisterio.

Massal, J. (2014). Revueltas, insurrecciones y protestas: un panorama de las dinámicas de movilización en el siglo xxI. Colombia: Instituto de Estudios Políticos y Relaciones internacionales (IEPRI), Universidad Nacional de Colombia. http://www.academia.edu/14551917/Revueltas_insurrecciones_y_protestas_._un_panorama_de_las_dinamicas_de_movilizacion_en_el_siglo_XXI

Maturana, H. (2001). Emociones y Lenguaje en Educación y política [Edición décima]. Dolmen Ensayo. https://es.slideshare.net/vivianamdg/humberto-maturana-emociones-y-lenguaje-en-educacion-y-politica-11708822 
Miller, L. (s.f.). Acción colectiva y modelos de racionalidad. IESA-cSIc. http://www.unavarra.es/puresoc/pdfs/c_ponencias/Miller.pdf

Moncayo, V. (2009). Una sociología sentipensante para América Latina. Orlando Fals Borda. Siglo del Hombre y Clacso. http://bibliotecavirtual.clacso.org.ar/ar/libros/coedicion/fborda/fborda.pdf

Olson, M. (1992). La Lógica de la Acción Colectiva. Limusa, Grupo Noriega.

Patzi, F. (2009). Sistema Comunal. Una propuesta alternativa al sistema liberal. Vicuño.

Romero, M. (2010). De la Competencia a la Compartencia en los cuidados transculturales. Index de Enfermería, 19 (23), 157-161. http://scielo.isciii.es/scielo.php?script=sci_ arttextpid=S1132-12962010000200019/ng=estlng=es.

Tarrow, S. (1997). El poder en movimiento: los movimientos sociales, la acción colectiva y la política. Alianza. https:// derechoalaciudadflacso.files.wordpress.com/2014/01/ sidey-tarrow-el-poder-en-movimiento-los-movimientos-sociales-la-accion-colectiva-y-la-politica.pdf

Torres, A. (2007). Identidad y política de la acción colectiva. Universidad Pedagógica Nacional.

Torres, A. (2013). El retorno a la comunidad, problemas, debates y desafios de vivir juntos. (Primera edición). Cinde - El Búho.

Torres, A. y Torres, A. (2015). Acción colectiva, gestión territorial y gobernanza. Universidad Piloto de Colombia.

Vasco, L. (2004). Entre selva y páramo. Viviendo y pensando la lucha india, nacionalidades indígenas y estado en Colombia. Instituto Colombiano de Antropología e Historia. http://www.luguiva.net/libros/sublndice.aspx?id=3

Zibechi, R. (2017) Movimientos sociales en América Latina. "El mundo otro" en movimiento. Ediciones Desde Abajo. 


\section{Diálogo del conocimiento}

Dialogar en torno al artículo "Acción colectiva de las redes magisteriales que hacen comunagogía" nos lleva a plantear cómo desde las colectividades docentes estamos trazando otra ruta posible del movimiento pedagógico iniciado en los años ochenta en nuestro país, para continuar con el legado de resistencia ante las políticas hegemónicas que se imponen en el curso de estas sociedades neoliberales y de mercado en las que el sujeto es anulado en beneficio del capitalismo que hoy por hoy toma el rostro de informacional o cognitivo.

Concuerdo con el autor en cómo el reconocimiento del quehacer pedagógico desde lo común da cuenta de dinámicas emancipatorias que trasgreden las fronteras disciplinares y espaciales de la cultura escolar para promover diálogos de saberes entre pares que permiten problematizar los contextos, los sujetos y las condiciones de vida que pugnan por una educación cada vez más digna, pluralista y democrática. Las reflexiones y propuestas en torno a la interculturalidad, la ciencia propia, la garantía y defensa de los derechos humanos, las estéticas y los múltiples lenguajes, la formación política, entre otros tópicos de discusión, hoy más que nunca se ponen en el centro de la formación de niños, niñas, jóvenes y comunidades, y son las redes magisteriales quienes se han dado a la tarea de hacerlas "sentipensar", es decir, latir en el seno de la producción de conocimiento.

Celebro que esta reflexión sea presentada por un maestro que recorre el territorio de la escuela y que tiene la sensibilidad para reconocer las voces de las colectividades que hacen eco en los discursos, saberes y prácticas de la pedagogía. No en vano, el pretexto que nos convoca es el de la "comunagogía"; una apuesta de sentido para no solo pensar la acción de las redes de docentes, sino la acción misma de nuestro quehacer como maestros constructores de saber e intelectuales de la educación desde el plano "nosótrico"; compartirlo, socializarlo y consolidarlo en comunitariedad es el desafío que nos debe seguir animando y la lectura de este artículo bien cumple con este cometido.

Ana Brizet Ramirez-Cabanzo, Ph.D. Coordinadora Licenciatura en Educación Infantil Universidad Distrital Francisco José de Caldas 